\title{
Managing the unseen: Langebaan Road Aquifer System
}

\author{
JA du Plessis* \\ Department of Civil Engineering, University of Stellenbosch, P/Bag X1, MATIELAND, 7602, South Africa
}

\begin{abstract}
The effective management of groundwater resources is a critical aspect to ensure sustainability. The paper discusses the structures used to ensure effective monitoring at a local government level, and focuses specifically on the process followed and the critical monitoring factors identified to ensure sustainability.

The paper highlights specific problems experienced with the implementation of the Langebaan Road Aquifer well-field as an integrated water resource, and the interaction required between the different role players. Suggestions, based on the Langebaan case study, are made regarding the different aspects to be monitored and the institutional arrangements required, ensuring effective participation between National and Local Government and other affected parties.

The paper concluded that an independent monitoring committee is of utmost importance to ensure the successful management of a sustainable groundwater resource. The lessons learned through the implementation of the Langebaan Road Aquifer proves that structured participation in the management of these resources is of critical importance and that success cannot be achieved without cooperation between all parties, in particular the different government departments.
\end{abstract}

Keywords: groundwater monitoring, management structures, sustainable groundwater

\section{List of abbreviations and acronyms}

DWAF $=$ Department of Water Affairs and Forestry

WCDM = West Coast District Municipality

MC $=$ Monitoring Committee

PSC $=$ Project Steering Committee

NWA $=$ National Water Act

NEMA $=$ National Environmental Management Act

EIA $=$ Environmental Impact Assessment

LRAS $=$ Langebaan Road Aquifer System

\section{Introduction}

As the pressure on existing surface water resources increases, groundwater resources are being looked into as the most logical alternative to be investigated. Often the value of groundwater as an alternative source only becomes known once the resources are being utilised.

In general, the challenge to manage groundwater properly does not receive adequate attention. The lack of proper knowledge and understanding of the working of such a resource is quite often the main reason for this. Engineers who normally manage these resources are often reasonably informed about the assessments of risks associated with surface resources, but the same cannot be said about the risks involved for groundwater resources, which are hard to visualise and difficult to measure.

NWA and NEMA complicate issues even further with aspects such as the 'Reserve' and compliance with procedures for a complete EIA as required by the relevant regulations.

This paper was originally presented at the 2008 Water Institute of Southern Africa (WISA) Biennial Conference, Sun City, South Africa, 18-22 May 2008.

* To whom all correspondence should be addressed.

甾 +2721 808 4358; fax: +2721 808 4351;

e-mail: jadup@sun.ac.za

\section{The West Coast challenge}

The West Coast of SA is not well endowed with surface water resources and with an average rainfall of approximately 300 $\mathrm{mm} / \mathrm{a}$, the development potential in this area is fairly limited due to a lack of adequate water supply. However, the excellent export harbour facilities at Saldanha and existing infrastructure like the Sishen/Saldanha railway line have resulted in extensive expansions in the steel industries at Saldanha Bay, putting more pressure on existing limited water resources.

The establishment of these industries in the late 1980s resulted in a steep increase in the water demand. With several new phases foreseen for the steel industry in 1987, the time had come to look intensively towards alternative resources to provide sufficient water for further development. During a public hearing process the Steyn Commission (Steyn et al., 1995), appointed by the Minister of Environmental Affairs and Tourism to investigate the possible environmental threat of a steel industry on the West Coast, concluded that, as part of sustainable development, groundwater needed to be evaluated as an alternative water resource before any further development could be allowed. Any future developments on the West Coast will put additional pressure on the Berg River system which is the main water resource for this area, as well as Cape Town.

The WCDM was at the time responsible for bulk water supply to the Saldanha area. In response to the Steyn Commission (Steyn et el., 1995) it was decided to investigate the possible development of groundwater resources in the Vredenburg area as shown in Fig. 1 to supplement the water supply to this area.

\section{Resources available}

One of the major groundwater resources available for further development in the study area is the Langebaan Road Aquifer System (LRAS). This water resource was proclaimed a Water Control Area under the previous (1956) Water Act in 1977, following extensive drilling and exploration work done by DWAF in the preceding 10 years. Two reports were produced by DWAF 


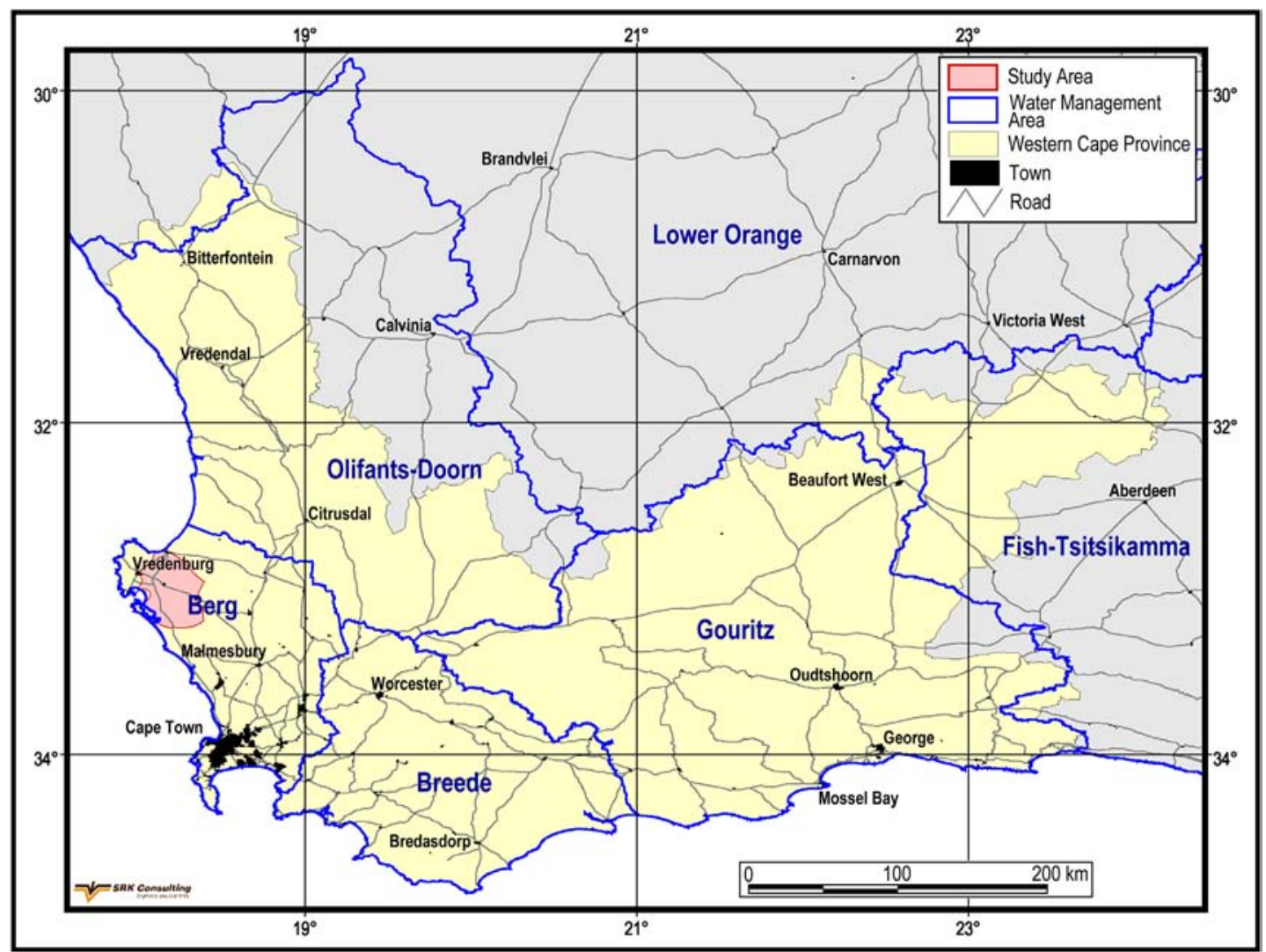

Figure 1

Study Area:

LRAS

(Timmerman, 1985a; b), indicating that an estimated $17 \mathrm{x}$ $10^{6} \mathrm{~m}^{3}$ of water was available for utilisation per year from LRAS. The WCDM's annual allocation from the Berg River system at the time was $21.64 \times 10^{6} \mathrm{~m}^{3}$ with a use of approximately $17 \times 10^{6} \mathrm{~m}^{3} / \mathrm{a}$ in 1998 . The LRAS groundwater resource was therefore considered to be substantial and worth further investigation.

LRAS consists mainly of a lower intergranular aquifer situated on granites and the Malmesbury formation at the bottom, with a clay layer above it. An upper intergranular aquifer is found on top of the clay layer, but the quality of the water is substantially poorer than the water found in the lower aquifer. The lower aquifer is considered to be confined, meaning that the water is basically under pressure underneath the clay layer.

The aquifer system is bordered by the Berg River to the north, the Salt River to the east and the Elandsfontein Aquifer System to the south. The Elandsfontein Aquifer eventually seeps into the Langebaan Lagoon, which is a declared RAMSAR site and of high environmental importance. Figure 2 shows the extent and the position of the aquifer system relative to other important formations.

Specific concerns about the extent of LRAS, the possible linkage between LRAS and the Elandsfontein Aquifer and thus the lagoon, as well as the possible linkage between the upper and lower aquifers, were some of the major concerns during the planning phase of the project.

\section{The process}

The process for the abstraction of water from LRAS commenced in 1996 with the principle decision by DWAF to continue monitoring the abstraction of $1.5 \times 10^{6} \mathrm{~m}^{3} / \mathrm{a}$. To guide the process a PSC was established. Although envi-

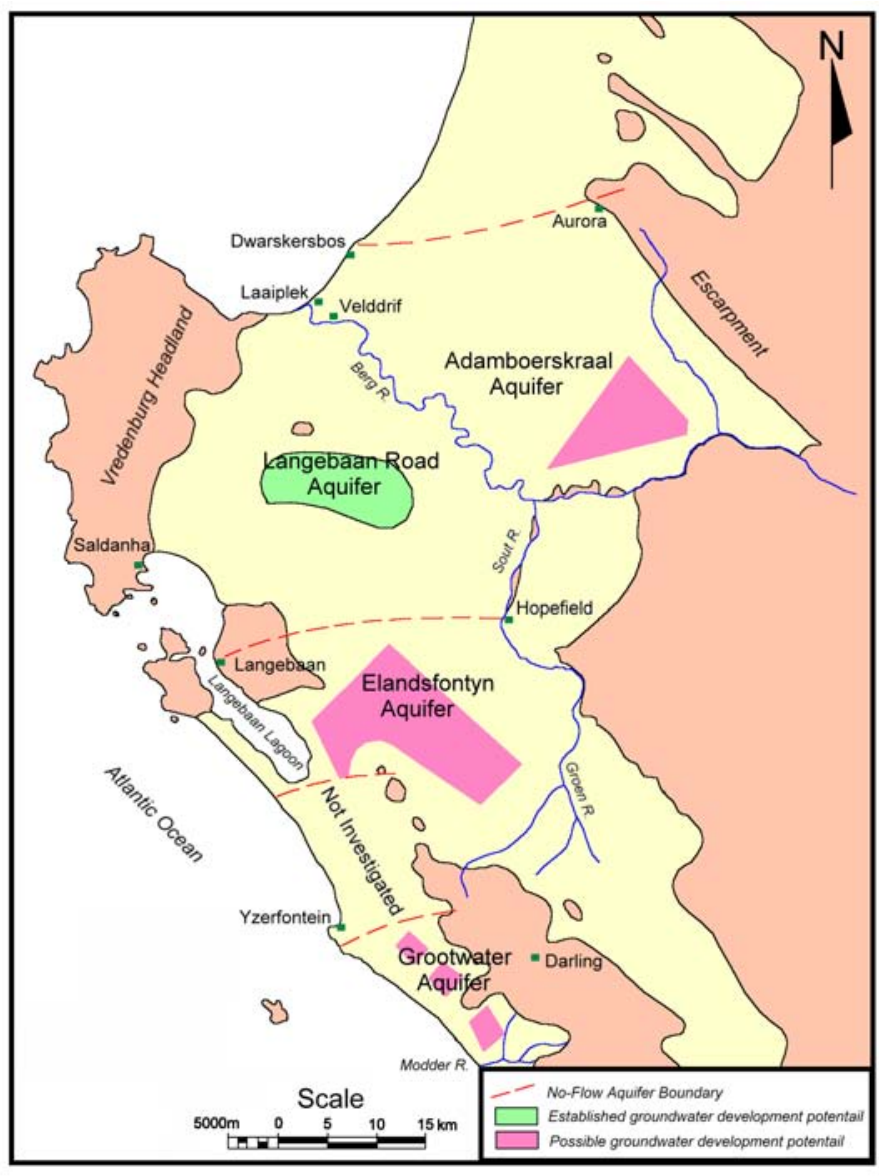

Figure 2

Extent and position of the LRAS in relation to other important formations 
ronmental legislation was not yet in place at the time, it was also decided to be proactive and to form a committee which included the farmers who were directly affected, as well as representatives from both DWAF and WCDM to be involved in the process. These stakeholders became the cornerstones for the successful implementation of the groundwater abstraction and the continued monitoring thereof.

\section{Project steering committee}

The project was considered to be a government water scheme, but since funds were not available at the time, WCDM agreed to provide all the capital funds required for the implementation of the project. They were also considered to be the implementing agent for the project and they accepted full responsibility for the operational side of the project after construction, as part of their existing function as the bulk water supplier to the region. As implementing agent, WCDM was also responsible for the appointment of all service providers, including the consultants for the design of the project.

One of the first steps required by DWAF was the establishment of a PSC. This formed the basis for the original co-operation between the different levels of government and ensured that all technical and legal requirements were met. The PSC was chaired by DWAF and was the co-ordinating body between WCDM and the following DWAF components: project planning, civil and mechanical design, construction, geohydrology, legal services and the Western Cape branch of DWAF.

The main functions of the PSC were to:

- Act as DWAF's official decision-making body

- Ensure that all aspects of the design were done properly (overseeing the consultants' design).

- Co-ordinate all the different role players

- Assume responsibility for surveys, permits and land matters

- Address all legal issues

- Assume responsibility for all policy decisions regarding the water resources

- Determine the Reserve, as required by the National Water Act of 1998

- Establish a monitoring network and the evaluation of the data.

\section{Monitoring committee (MC)}

The need to manage the day-to-day activities required the establishment of a technical committee, which included officials from DWAF's regional office, WCDM, consultants and the geohydrologist involved in the design of the project. After 8 monthly meetings it was decided in 1998 to broaden the scope of the technical committee to also include representatives from other government departments, the local farming community and other interested parties. The 'Saldanha Groundwater Government Scheme Monitoring Committee' was formed. This committee found itself well positioned soon after its establishment to adhere to one of the critical conditions, i.e. the establishment of a monitoring committee, as stated in the Record of Decisions, after the EIA had been undertaken in 1998.

This committee developed into a forum where a number of critical issues were discussed and proposals were made for decisions to be taken either by DWAF, through the PSC, or WCDM, through council decision.

Membership of the monitoring committee was considered to be open to representatives of organised groups as long as a group could prove its interest and contribution to the development. Individual with specific interests and knowledge could also be invited by the MC. All costs for attending meetings were met by the member's organisations and no re-imbursement was provided by DWAF or WCDM.

The MC included the following parties:

- Officials from WCDM

- Officials from the DWAF (including geohydrologists, environmental officials and the catchment manager for the area)

- A representative of the local farmers, through the relevant official farming structures

- A number of individual farmers with fairly large properties in the area of interest

- A representative from Agriculture: Western Cape.

- A representative from Agriculture: Soil Conservation

- Cape Nature Conservation

- A representative from the Langebaan Road Air Force Training School which is situated directly above the resource

- National Parks Board (West Coast National Park)

- A representative from Saldanha Steel, the main industry responsible for the additional demand in water resources

- A representative from the environmental monitoring committee established by the Minister of Community Safety and Environmental Affairs to monitor the impacts of the steel industry during construction and for a short period thereafter

- A representative of a number of smallholdings also situated above the resource that have the potential to impact on the resource.

\section{Technical challenges}

The basic questions asked during the development of a groundwater resource can be summarised as follows:

- How much water can be abstracted safely from the resource?

- What is the Reserve to be allowed for according to the Water Act?

- Which factors need to be monitored during the abstraction phase to ensure sustainability?

- What should be done if a preset condition is violated during abstraction?

- In the case of possible environmental damage, can the process be reversed?

Since this project was considered to be a government water scheme, it was primarily the responsibility of DWAF to ensure that all these questions be addressed properly. In practice this was done through the MC, while the PSC was mainly responsible for the project from a policy point of view.

\section{Safe yield}

Timmerman (Timmerman, 1985a) set the short-term yield of LRAS at $19.5 \times 10^{6} \mathrm{~m}^{3} / \mathrm{a}$ and the long-term yield at $30 \times 10^{6} \mathrm{~m}^{3} / \mathrm{a}$. These calculations were based on a $15 \%$ recharge from rainfall. The CSIR re-evaluated these figures during the WCDM investigation phase and reported that LRAS has a maximum yield of 13 $\mathrm{x} 10^{6} \mathrm{~m}^{3} / \mathrm{a}$, while the safe yield can be accepted as $7.8 \times 10^{6} \mathrm{~m}^{3} / \mathrm{a}$, based on $8 \%$ recharge (Weaver et al., 1997).

At the same time pump tests were carried out on existing boreholes drilled about 20 years ago and these were found to be capable of supplying the $4000 \mathrm{~m}^{3} / \mathrm{d}$ required by WCDM. After an evaluation of the cost to supply the bulk infrastructure to link 
the existing boreholes with the existing water infrastructure, it was decided to establish a new well-field and 10 new boreholes were drilled. Four were considered as production boreholes and, according to pumping tests, were able to deliver $25 \mathrm{l} / \mathrm{s}$ (24 $\mathrm{h} / \mathrm{d}$ ). Based on these findings by Weaver and Fraser (1988 a) the project was launched and construction started.

It was recognised, however, that more information had to be obtained to fully understand the magnitude of the aquifer system and the mechanisms responsible for its functioning, and so it was suggested that additional boreholes be drilled in areas of uncertainty. Environmental isotopes were also sampled to better understand the age of the water and the source of recharge.

The modelling done by the CSIR, based on the Timmerman report (Timmerman, 1985b), assumed that the lower aquifer is semi-confined and thus allows for some leakage between the upper and lower aquifers. After the testing was done on the new boreholes an addendum (Weaver and Fraser, 1998b) to their report (Weaver and Fraser, 1998a) was issued, stating that the clay samples obtained from all the boreholes drilled did not contain any sand, and the consistency was thick and sticky. The clay layer was therefore considered to be impermeable and the lower aquifer fully confined in the well-field area. This finding did not change the capacity of the resource, but the way in which the aquifer would respond to abstraction. It was thus likely that the boreholes sunk into the bottom aquifer would experience a steeper drop in the water table (pressure drop) once pumping commenced, than had originally been anticipated.

The challenge for the MC at this stage was and still remains, in part, to understand that the aquifer can ONLY be fully understood by utilising it and closely monitoring its reaction to abstraction.

\section{Aspects to be monitored}

The CSIR listed a number of issues that needed to be addressed in their monitoring report (Weaver et al., 1997) as part of a suggested management plan for the resource. These included the following:

- Monthly water levels

- Rainfall

- Pump volumes

- Water levels during pumping

- Monthly monitoring meetings.

In a subsequent CSIR report (Weaver and Fraser, 1998b) on the test results of the newly established well-field, the issue of water quality was discussed in more detail and it was recommended that the monitoring programme be extended to also include water quality at the production boreholes as well as outside the production field. Two aspects were highlighted to be the focus point of the monitoring:

- Over-abstraction of the resource and

- The intrusion of bad-quality brackish water from the surrounding areas.

A number of monitoring points were identified in both the upper and lower aquifers to act as monitoring network. At the time 53 points were monitored, 28 in the upper aquifer and 25 in the lower aquifer. Five boreholes in the upper aquifer were used for quarterly macro- and trace-element analyses and 10 in the lower aquifer. Six monitoring points were used in the upper aquifer for monthly electrical conductivity readings and 2 in the lower aquifer.

In order to execute the recommendations in the CSIR report (Weaver and Fraser, 1998a) and the Record of Decisions from the EIA process, the MC recommended to DWAF that an independent geohydrologist (Toens and Partners) be appointed to focus specifically on the following main points:

- Establish a geohydrological database

- Make recommendations to extend the existing monitoring system to also include the Elandsfontein Aquifer

- Report bi-annually on the response of the well-field.

Toens and Partners used, where possible, existing data as baseline data and produced their $1^{\text {st }}$ monitoring report (Woodford, 2000) 7 months after production started. This report presented the MC with the first set of data to be used for evaluation, although at a very early stage. A number of graphs were produced with Fig. 3 showing a typical response of the upper aquifer before and during pumping.

A number of critical issues were highlighted. It was clear that the water level in the upper aquifer showed a tendency of dropping long before any pumping started. Some of the monitoring points were utilised by farmers through wind pumps and showed sudden drops with steep recovery recorded directly afterwards. This action is also reflected in the electrical conductivity measurements at a number of monitoring points. It was decided to reject these points as being unrepresentative and to add a number of new points.

A $2^{\text {nd }}$ monitoring report (Woodford, 2001) was presented by Toens and Partners, covering the period December 1999 till March 2001. The results showed no problems and it was recommended that the abstraction of $4000 \mathrm{~m}^{3} / \mathrm{d}$ be maintained. New monitoring points were once again identified to either replace

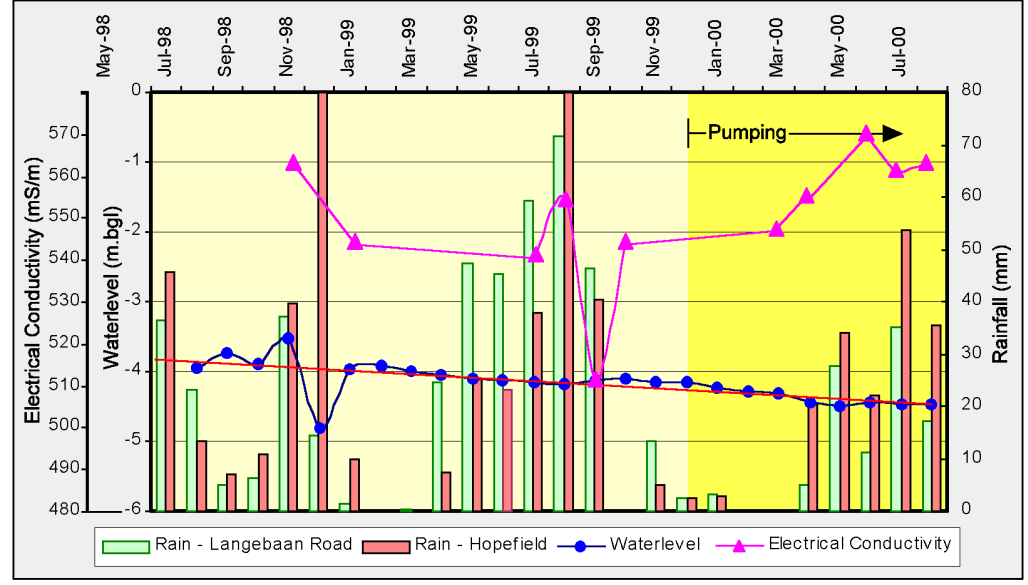

Figure 3

Monthly Rainfall, EC's and Water level fluctuations in the Upper Aquifer 
problematic monitoring points or to be added as additional points.

\section{Early warning}

A critical responsibility of the MC was to evaluate the monthly monitoring data and to ensure that appropriate steps be taken if the monitoring data indicated unacceptable response as a result of abstraction. The question, however, was: What is an unacceptable response and against which values are the monthly monitoring data compared with?

In terms of the drop in the water levels in the lower aquifer, it was suggested to assume that, since the resource was classified as a confined aquifer, a drop in the water level to such an extent that it might change the flow regime, should be prevented. The clay layer, being the cause of the 'confined' nature of the lower aquifer, was in general about $30 \mathrm{~m}$ thick. It was therefore considered to be safe to allow the water levels in the lower aquifer to drop until they reached this layer, but they should not be allowed to drop below the clay layer. A value of an 'acceptable' level of $10 \mathrm{~m}$ below the top of the clay layer was set as a danger point by the MC.

A drop of $0.5 \mathrm{~m}$ in the upper aquifer's water level was set arbitrarily as the warning point by the MC, but it was stressed that decisions based on this value should be considered extremely carefully. Any changes in the existing EC levels should be considered as a warning point, taking seasonal variations into consideration.

The setting of warning points remains one of the contentious issues within the MC. From a practical point of view, it is clear that no fixed values can be given, but that the full picture needs to be considered before a decision regarding the abstraction can be made.

\section{Environmental challenges}

Environmental aspects are well integrated in all aspects of the development of an aquifer and although the project started before the implementation of NEMA, it was decided to follow a complete environmental impact assessment procedure as required by NEMA. Independent consultants were appointed to manage the process for the WCDM. The WCDM was the applicant since they were responsible for the abstraction of the water. After a full public participation process, the activity to abstract 4000 $\mathrm{m}^{3} / \mathrm{d}$ was approved under a number of conditions. These conditions include, among others, the establishment of a monitoring plan to specifically include indicators to be measured against and to act as early warning system.

The process was, however, delayed due to an appeal lodged by the affected farmers against the approval of the project. After the appeal was heard by the Minister of Community Safety and Environment Affairs, the decision to proceed with the abstraction was confirmed, but included a number of additional conditions.

The most significant additional requirement set by the Minister, was that additional work needs to be done to establish the possible link between the Elandsfontein Aquifer and LRAS. It was furthermore agreed that the monitoring programme need not to be a fixed document, but should be developed as data became available.

To date, this process continues to deliver valuable data. It is clear that there will almost certainly never be enough data to be able to state that the resource is fully understood. Eventually, it results in a compromise of spending enough money to obtain enough information to be reasonably confident in the predictions regarding safe yields and storage capacity.

The MC plays an extremely important role in this regard. As stated before, the 1998 Record of Decision, resulting from the EIA process was one of the main reasons for the existence of the MC. The process did, however, open a number of critical issues relating to the members who serve on the MC. The 1998 Record of Decision stipulates only that the monitoring plan needs to be made available to interested and affected parties for their input. The implication is that, once their input has been received and the plan has been approved by provincial and national organs of state, the function of the interested and affected parties basically ceases. As long as reports, as agreed upon, are being delivered to the relevant authorities for approval, the process is considered to be completed.

For a number of reasons Government officials are presently, under tremendous workload pressure, and the capacity to evaluate groundwater resources remains limited. The LRAS process proves that continuous input from interested and affected parties serves the cause of the project well, and the process should be developed further to benefit all similar projects. Members of the MC need to be identified and selected carefully to ensure a functional committee which can contribute towards the main objective of the project.

\section{Recommendations}

Since groundwater abstraction can have a substantial influence on a number of environmental aspects in specific instances, monitoring of significant abstractions need to be done in a more structured way. Based on the lessons learned from the LRAS experience, the suggested role of the MC is the following:

- The establishment of an MC needs to be compulsory

- An independent geohydrologist needs to be appointed by the MC and paid by the organisation responsible for the activity to assist in the monitoring

- DWAF, needs to take responsibility for the monitoring of the abstraction and should therefore also take the responsibility for the forming and funding of the MC and process (but not necessarily the equipment needed)

- Members of the MC should be nominated carefully: - Ensure that the best possible representation is achieved

- Nominees ought to have a basic knowledge of the subject as the evaluation of the data is time-consuming

- Members not affiliated to specific organisations, but who serve on the MC due to their special knowledge, should be compensated for their travelling expenses

- Highly specialised individuals can and should be incorporated on an ad hoc basis to deal with specific issues

- The MC should report back to all interested and affected parties on a regular basis through public meetings.

\section{Conclusion}

The management of the abstraction of groundwater can be a very complicated exercise and needs to be monitored closely. The PSC worked well in the LRAS case and ensured that highly technical issues like servitudes and design problems were dealt with in a very effective manner. Continuous input from all interested and affected parties can contribute towards a better understanding of the resource and needs to be incorporated in a well-structured MC. Members of the MC should, however, be selected carefully to ensure effective participation and the independence of such a committee was found to be of utmost importance in the 
LRAS case. A complete record of all the proceedings proves to be extremely valuable and saves the MC much debate and time. A special effort needs to be made to ensure that the members of the MC trust the system.

Given the nature of the exercise and the amount of time required to evaluate the monthly data collected in this case, it will most definitely be of value if the individuals serving on the committee on behalf of an organisation without a financial backing, could be paid for actual expenses incurred.

The MC needs to establish baseline monitoring levels against which to measure the performance of the aquifer as early as possible. Steps to be taken if these benchmark values are reached need to be in place. Monitoring is, however, a long-term process with new critical areas to be monitored being identified as more and more data become available. Baseline values therefore need to be set with long-term responses in mind and not too much value should be given to changes in these levels over a specific season.

Groundwater resources can only be understood fully if they are utilised and monitored closely. Monitoring is an ever-changing process which should not be neglected and which should be used to the benefit of all parties involved towards the better understanding of the resource.

\section{Acknowledgement}

The author wishes to thank the Monitoring Committee, the West Coast District Municipality and the Department of Water Affairs and Forestry for allowing him to publish this information. A special thanks to SRK (Pty) Ltd for making available the relevant graphs used in this paper.

\section{References}

STEYN JH, FUGGLE RF and MARUMA R (1995) Report of the Board of Investigation into the Saldanha Steel Project. Department of Environmental Affairs and Tourism. Unpublished. Cape Town, South Africa.
TIMMERMAN LRA (1985a) Langebaan Road Aquifer. Possibilities for the Development of Groundwater from Cenozoic sediments of the Lower Berg River region. Report GH3374. Department of Water Affairs and Forestry. Cape Town, South Africa.

TIMMERMAN LRA (1985b) Langebaan Road Aquifer. Preliminary Report on the Geohydrology of the Langebaan Road and Elandsfontein Aquifer Units in the Lower Berg River Region. Technical Report GH 3373. Department of Water Affairs \& Forestry. Cape Town, South Africa. August 1985.

WEAVER JW and FRASER L (1998a) Langebaan Road Aquifer Unit - Drilling and Testing of New Wellfield. Technical Report ENV/SC98042. Division of Water, Environment and Forestry, CSIR, Stellenbosch, South Africa. May 1998.

WEAVER JW and FRASER L (1998b) Langebaan Road Aquifer (LRA) Re-Modelling of the Expected Drawdowns. Report No ENV/SC98042 (Addendum). Division of Water, Environment and Forestry, CSIR, Stellenbosch, South Africa. May 1998.

WEAVER JW, VAN DER VOORT I, HÔN A and CONRAD J (1997) Langebaan Road Aquifer Unit - Water Supply Project. Technical Report ENV/S-C97015. Division of Water, Environment and Forestry, CSIR, Stellenbosch, South Africa. February 1997.

WOODFORD AC (2000) Preliminary Assessment of the Performance of the Langebaan Road Wellfield and Geohydrological Monitoring Network. Toens \& Partners. Technical Report No. 2000239. Wynberg. Cape Town, South Africa. September 2000.

WOODFORD AC (2001) Assessment of the Performance of the Langebaan Road Wellfield and Geohydrological Monitoring Network. Toens and Partners. Report No 2001249. Department of Water Affairs and Forestry, South Africa. March 2001.

WOODFORD AC (2005a) Assessment of the Response of the Langebaan Road Aquifer System to a 3 month Shutdown of the Municipal Wellfield. SRK Consulting Engineers and Scientist. Report No 335975. West Coast District Municipality, South Africa. February 2005.

WOODFORD AC (2005b) Assessment of the Performance of the West Coast District Municipality's Well Field and Geohydrological Monitoring Network. SRK Consulting Engineers and Scientist. Report No 350021. West Coast District Municipality. August 2005. 